on the EN aetiology, the main symptoms were fever (in 38 patients), joint pain (in 41 patients), foot and leg oedema (in 44 patients). The duration of EN syndrome before beginning meloxicam was from 2 weeks to 4 months. During this period all the patients underwent therapy by various NSAIDs (mainly diclofenac, ketoprofen, indometacin), 4 patients by steroids, antibiotics. In all the patients the previous therapy was either noneffective or little effective. Using meloxicam as a monotherapy on the 2-nd, 3-d day of taking the drug resulted in normalisation of temperature, disappearance of joint pain and oedema, quick decreasing of EN even in those patients who had no effect from steroids. In 4 patients the attempt of cancelling meloxicam lead to relapse of EN, fever and joint pain, which demanded resuming of meloxicam treatment. 4 patients had an allergy in the form of skin eruption and itch. That?s why meloxicam in those patients was cancelled in spite of a good effect. Meloxicam turned out to be ineffective in 2 patients. In 45 patients $(95.7 \%)$ with pronounced EN, fever and oedema meloxicam showed great effectiveness.

Methods

Results

Conclusion

\section{AB0086 OCCURRENCE OF GIANT CELL ARTERITIS UNDER METHOTREXATE THERAPY FOR RHEUMATOID ARTHRITIS}

J Gerster, I Carey, AM Chamot. Department of Rheumatology, University Hospital (CHUV), Lausanne, Switzerland

\subsection{6/annrheumdis-2001.193}

Background There is controversy about methotrexate (MTX) as a therapy of giant cell arteritis (GCA).

Objectives The objective is to present a case who developed GCA during therapy with MTX in association with corticosteroids for rheumatoid arthritis.

Methods A 66-year-old-woman was diagnosed in 1998 as seronegative rheumatoid arthritis involving knee, shoulder and wrist joints. ESR was $46 \mathrm{~mm} / 1 \mathrm{~h}$, synovial fluid contained $29 \mathrm{G} / \mathrm{L}$ leukocytes but no crystals were observed. The patient was treated with MTX at a weekly dose of $7,5 \mathrm{mg}$, dosage increased to 10 $\mathrm{mg} /$ week in February 2000. In addition, she received prednisone $5 \mathrm{mg}$ per day. In November 2000 she started to feel some weakness and to suffer from frontal headaches. The ESR was 120 $\mathrm{mm} / 1 \mathrm{~h}, \mathrm{CRP} 121 \mathrm{mg} / \mathrm{l}$ and $\mathrm{Hb} 80 \mathrm{~g} / \mathrm{L}$. The biopsied right temporal artery, which was tender and indurated, demonstrated GCA. The internal elastic lamina was fragmented; there were infiltrates of histiocytes, lymphocytes and giant cells and the lumen was in some places occluded.

Results

Conclusion In this case, occurrence of GCA was not prevented by MTX therapy. This suggests that MTX at an average dose is probably insufficient to prevent or treat this disease.

\section{AB0087 TAKAYASU'S ARTERITIS: REVIEW AND FOUR CLINICAL CASES}

G Sequeira, F Saraiva, A Marques, J Romeu, T Costa, V Queiroz. Medicine IV C, Hospital de Santa Maria, Lisbon, Portugal
Background Takayasu's arteritis is a rare disease, mainly affecting young women. The authors describe four cases of Takayasu's disease from the rheumatology outpatient clinic of Hospital de Santa Maria in Portugal. A revision of the disease is made concerning it's clinical manifestations, laboratory, diagnosis, treatment and prognosis.

Objectives

Methods

Results All patients were female, three were white and one black. Begining of symptoms was between 7 and 56 years, satisfying the American College of Rheumatology criteria for the classification of Takayasu's arteritis. The spectrum of presentation, disease activity and pace of disease progression were very variable. The delay between the onset of first symptoms and diagnosis was less than three years in three patients and twenty in the other. The first symptoms of disease were in two patients systemic reactions such as malaise, fever and anorexia, absent pulses in the lower limbs in another and claudication of the upper extremities in the last. Vascular ischaemic symptoms, hallmark of the disease, were present in the four patients and all of them had angiograms that involved visualisation of at least primary tributaries that showed lesions of the aortic arch and its branches. All patients needed corticosteroid treatment in the acute inflammatory phase of the disease. Cytotoxic agents were used in three of them and in two cases vascular surgery was done because of fear of occlusion of the involved vessels.

Conclusion Females and caucasian race predominated. The diagnosis of Takayasu's arteritis should be considered in the presence of symptoms of vascular ischemia such as pulse defects or signs of bruits and in the angiografic study. The prominence of inflammatory features antedating obvious symptoms often delayed diagnosis for substantial periods of time. Fever, myalgia/arthralgia with no identified cause, elevated erythrocyte sedimentation rate, claudication, diminished or absent pulses, bruits, vascular pain and the typical angiographic features are criteria for disease activity. The mainstay of treatment is oral corticosteroids. They are very effective in controlling clinical manifestations and arresting disease progression and sometimes in achieving return of previously absent pulses. Cytotoxic therapy has been helpful in patients failing to respond to corticosteroids.

\section{AB0088 PULSE CYCLOPHOSPHAMIDE THERAPY IN A PATIENT OF GIANT CELL ARTERITIS WITH DIPLOPIA DUE TO UNILATERAL ABDUCENS NERVE PALSY}

JC Tseng, HH Cheng, RJ Hu, LY Lu. Allergy, Immunology and Rheumatology, Veterans General Hospital, Kaohsiung, Taiwan, R.O.C

\subsection{6/annrheumdis-2001.195}

Background Patients with giant cell arteritis (GCA) occasionally complain of double vision. The neurologic manifestations of the GCA are protean. All parts of the visual pathway from the cornea to the cortex have been described to be involved.

Objectives We described a patient of GCA with diplopia due to left abducens nerve palsy which was refractory to corticosteroid therapy initially and recovered with monthly pulse cyclophosphamide therapy five months later. To the best of our knowledge this is the first case described in the medical literature to be treated with monthly pulse intravenous cyclophosphamide and to achieve a successful outcome.

Methods

Results 